\title{
Chinese law aims to quell fear of failure
}

\section{BEIJING}

In a bid to encourage scientific risk-taking and to curb rampant misconduct, China is planning to legislate for failure. A law proposed by the Ministry of Science and Technology (MOST) would allow Chinese scientists to report failures in their research without jeopardizing their chances of future funding. But critics say that policies with real impact, such as establishing systems for effective evaluation and oversight, are needed more urgently.

"Chinese researchers are under tremendous pressure to produce results," says Cheng Guodong, a geoscientist at the Cold and Arid Regions Environmental and Engineering Research Institute in Lanzhou, Gansu province. "Their performance in the lab has a domino effect on other aspects of their life, such as promotion, salary and social benefits. So the stakes are high if they fail."

Some believe that a consequent fear of failure is preventing Chinese scientists from taking risks, and results in research misconduct across the country. According to the draft law, failure of research projects would not have any professional bearing on researchers as long as they could demonstrate that the experiments were well thought out and properly conducted, says Xue Lan, executive vice-president of the Development Research Academy for the 21st Century at Tsinghua University, Beijing, who heads the team that has drafted the proposal.

It was announced on 26 August, the day before the international Organisation for Economic Co-operation and Development released a report calling for improved innovation capacity in China. In 2005, China became the world's sixth biggest spender on research and development, and it currently has more researchers than any country apart from the United States. But the report, commissioned by MOST, concludes that China has a long way to go in building the mature, national innovation system it wants.

Some commentators say that China needs to introduce radical reforms to improve its innovation capacity. But is the proposed legislation for failure the right way of going about it? Li Gong, chief executive of Mozilla Online, the Beijing subsidiary of the global software company, is not convinced. "The starting point of the proposal is fundamentally flawed. The definition of failure in research is problematic because negative results also yield knowledge," he points out.

\section{"Risk-taking is the} most important aspect in science."

"This is a useful but small step," says Muming Poo, a neuroscientist at the University of California, Berkeley, and director of the Institute of Neuroscience in Shanghai. But the proposed amendment is built on the premise that there is critical appraisal of a project's success or failure in China, which is not the case, he says. Many researchers believe that the lack of a transparent evaluation system is the real reason for the poor performance of China's scientists and that this needs to be tackled urgently. "Without that, everything will fall apart," says Cheng.

"Fear of failure is only partly responsible for rampant research misconduct in China," says Bai Lu, a neuroscientist at the National Institute of Child Health and Human Development in Bethesda, Maryland. "At the heart of the matter is that there is no effective oversight mechanism to ensure that fraudsters do not go unpunished. The lack of a culture of accountability is a much broader and deeper issue."

According to the newspaper China Daily, the draft law says that principal investigators should establish credibility records for their staff in order to curb fraud, and asks researchers to be 'self-disciplined'. "But self-discipline is not enough," says Lu. "That's the point."

Despite the criticisms, the proposed law has its supporters. Duan Yibing, a sciencepolicy researcher at the Institute of Policy and Management in Beijing, explains that basic laws carry supreme authority in China, so legislation that recognizes the intrinsic risks associated with research and is tolerant of failure would send a powerful signal.

"Risk-taking is the most important aspect in science, so China is doing the right thing," says Raghunath Mashelkar, president of the Indian National Science Academy in New Delhi. "The law would influence the way researchers and funding agencies behave and generate an environment conducive to innovation." In India, Mashelkar has successfully carved out a niche for innovation by setting up special funds, such as the Kite-Flying Fund and the New Millennium Indian Technology Leadership Initiative, for high-risk projects, a strategy he thinks may offer China some useful lessons.

Legislation alone would not be enough to cause fundamental change in the culture of scientific research in China, acknowledges an employee at MOST, who wishes to remain anonymous. He says that a series of supporting regulations and policies, including those for improving appraisal and oversight systems, are already under discussion. "The law would not only provide a guiding principle for formulating those rules but a significant impetus for their implementation," he says.

The proposed law is being deliberated by the Standing Committee of the National People's Congress, China's top legislature. A decision is expected to be made next March.

Jane Qiu 